\title{
River Channel and Tidal Bar Deposits Gaspe Nord, Quebec*
}

\author{
W. R. COSTELLO
}

Massachusetts Institute of Technology, Cambridge, Mass.

A preliminary study of the rivers and streams draining into the St. Lawrence Estuary from the Gaspe Peninsula indicates that large amounts of glacial sediments and newly eroded Paleozoic rocks are being transported to the coast. Much of the sediment that is being supplied to the intertidal area is in the size range of medium sand to gravel. The nature and extent of these coarse sediment deposits can be seen in the extensive development of gravel bars in the midchannels of the rivers draining into the estuary.

\section{Source}

The rivers and streams of the Gaspe Nord area drain from high mountain areas adjacent to the coast. The bedrock, which the rivers erode and transport as bedload, is the Middle Ordovician flysch deposit of the Cloridorme Formation. These rocks consist of thin alternating beds of shale, sandstone, and less commonly limestone (Enos, 1969).

The valleys in which the streams flow are steep-sided as a consequence of glacial scour. The floors of the valleys contain large accumulations of coarse glacial outwash sediments. These sands and gravels are deposited either as small moraine strands across the width of the valleys or as a broad outwash plain. The rivers have incised these Pleistocene deposits and have incorporated the sediment into their load. Owing to a combination of natural weathering phenomena and the very steep sides of the valleys, more gravel-sized sediment is supplied to the valley floors in the form of debris slides. Short tributary streams, draining into the main channel from the valley sides, transport the disintegration products of the Paleozoic debris.

\section{River Competency}

The upper and middle reaches of the streafns and rivers have a steep gradient and also a high velocity of flow. During the spring runoff, the surface waves upon the rivers can be seen to migrate upstream, indicating an upper flow regime. On the middle reaches of the Riviere de la Grande-Vallee, gravel-sized sediment (pebbles up to two inches in diameter) was observed to be rolled continuously along the bed of the river. The water surface waves indicate a Froude number close to unity in a channel four feet deep. Calculations then give an estimated flow velocity of 10-12 feet per second. Such a flow velocity agrees well with the observed sediment movement (Hjuilstrom, 1935).

Where small, steep tributary streams enter the main channels, gravel is accumulated, and mid-channel bars then develop. This indicates that gravel-sized sediment is being supplied to the rivers at the present time. Further evidence on the competency of the rivers is shown in the active bank erosion of the glacial sediments deposited on the valley floors (Fig. 1).

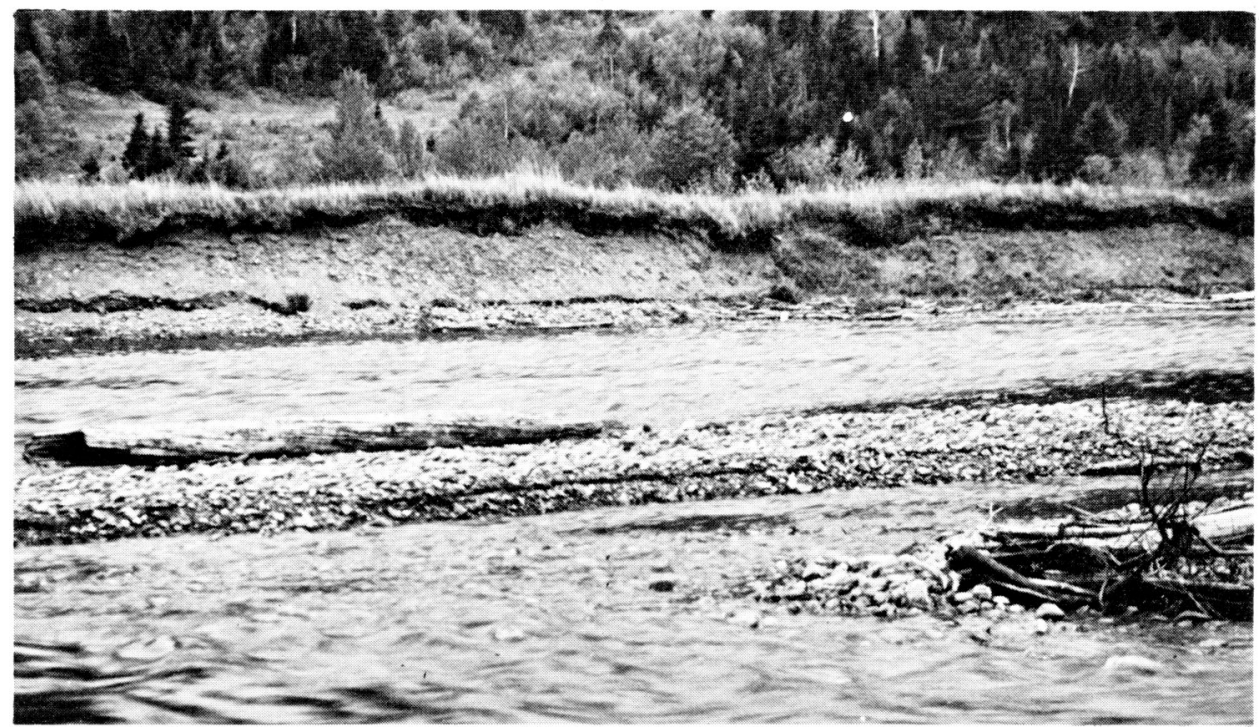

Figure 1-Bank erosion of Ple istocene gravels and mid-channel bar development. Flow to right.

* Manuscript received July 7, 1970. 


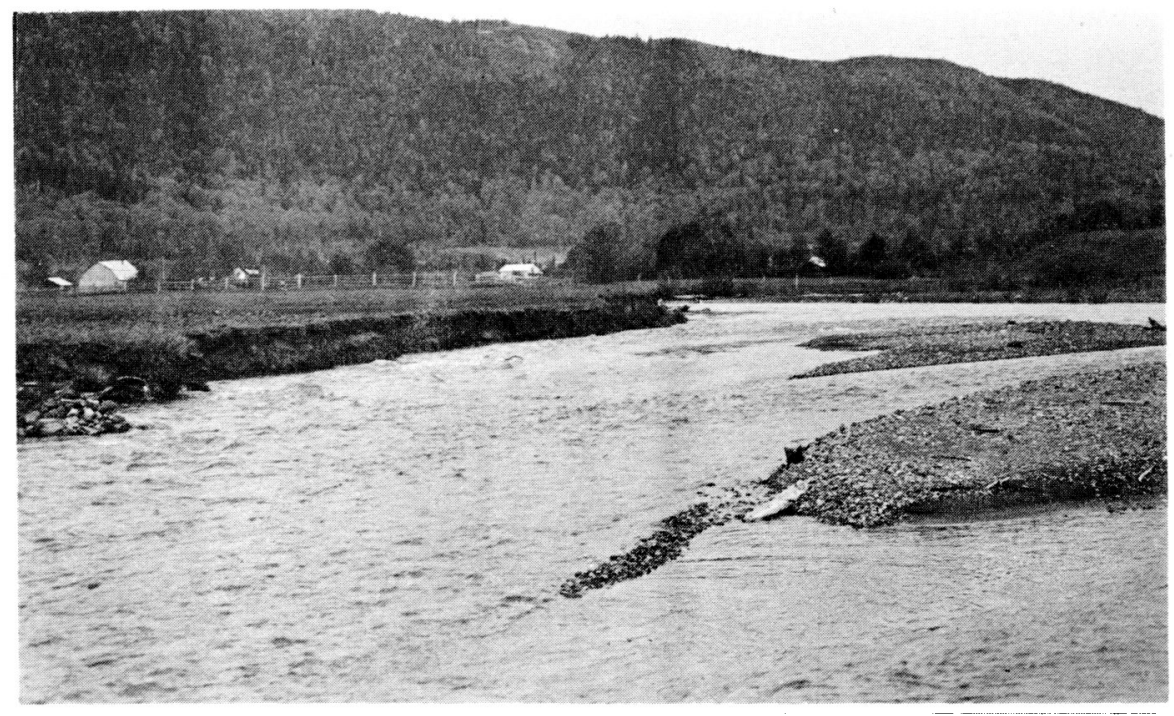

Figure 2 - Gravel bars on a braided reach of the Riviere de la GrandeVallee. The bar is growing by addition of gravel to its downstream end. Flow towards observer.

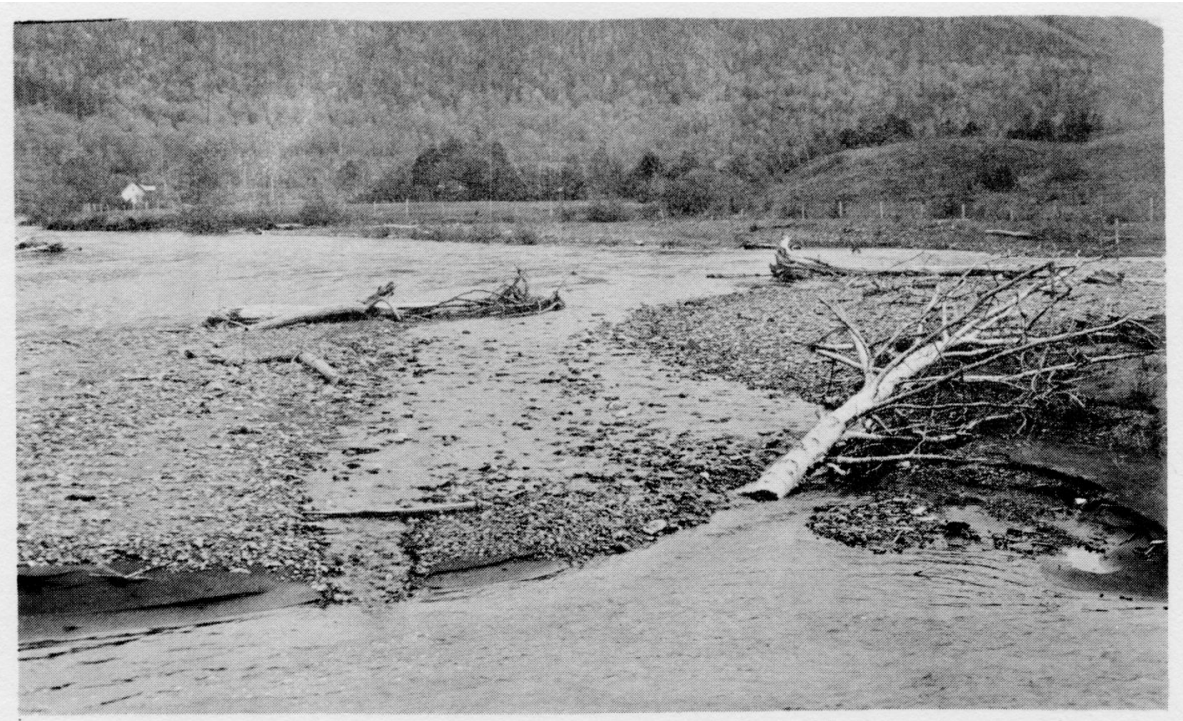

Figure 3 - Gully cut in a bar by a small stream. Note the sand trapped on the sheltered lee slope.

\section{Bar Development}

The gravel bars are nearly always deposited in the middle of the river channels (Fig. 2). The bars are rhombohedral in shape and elongated parallel to the river. The maximum observed length of the bars was 150 feet, and the maximum width was 60 feet. The bar elevation is asymetrical, in that both the downstream edge and the edge nearest a river bank (if a bar lies close to one bank of the river) are topographically higher than the other parts of the bar. One gravel bar was observed continuously for a period of six hours and was noticed to grow in length by additions of gravel to its downstream end. In many mid-channel bars the downstream edge was constructed as a steep avalanche face. Small streams cut obliquely over the bar surface at periods of low discharge, and cut across the bar to the side nearest the river bank (Fig. 3). This feature is probably due to a transverse component of flow in the river, i.e., a secondary current.

With the deposition of mid-channel bars, the rivers take on a braided pattern. The initiation of deposition and bar development results from a lowering of the flow velocity and hence the competency of the river (Leopold and Wolman, 1957). Since the velocity of flow is dependent upon the slope of the river channel, it is to be expected that changes in the slope of the river can be related to the occurrence of gravel-bar development.

The lowest gradients of the river systems are in those areas adjacent to the St. Lawrence Estuary. It is also in the area closest to the coast that tidal fluctuations cause alternate 
rises and falls in the base levels of the rivers. At high tide, the river water backs up and undergoes a local lowering of its surface slope, which in turn causes a decrease in the flow velocity. It is in the areas of the river which are affected by tides that the mid-channel gravel bars are most abundant. These gravel bars are here termed tidal bars.

\section{Tidal Bars}

During high tide the tidal bars are submerged. As this is also a period of backup in the river drainage, the velocity and competency of the river are decreased, and sand and gravel are seen to accumulate on the bar surfaces. With a lowering of the tide and an increase in the surface slope and velocity of the rivers, fines deposited on the bar surfaces are largely swept away. Sand trapped beneath or in the lee of large pebbles or cobbles or in sheltered depressions is protected from erosion (Fig. 4). As a result, harrow marks and current crescents are left upon the bar surfaces. A few higher bars which remain above water at high tide display excellent imbrication of large, flat cobbles and pebbles (Fig. 5). These bars are evidently affected by stronger river flows during flood discharges.

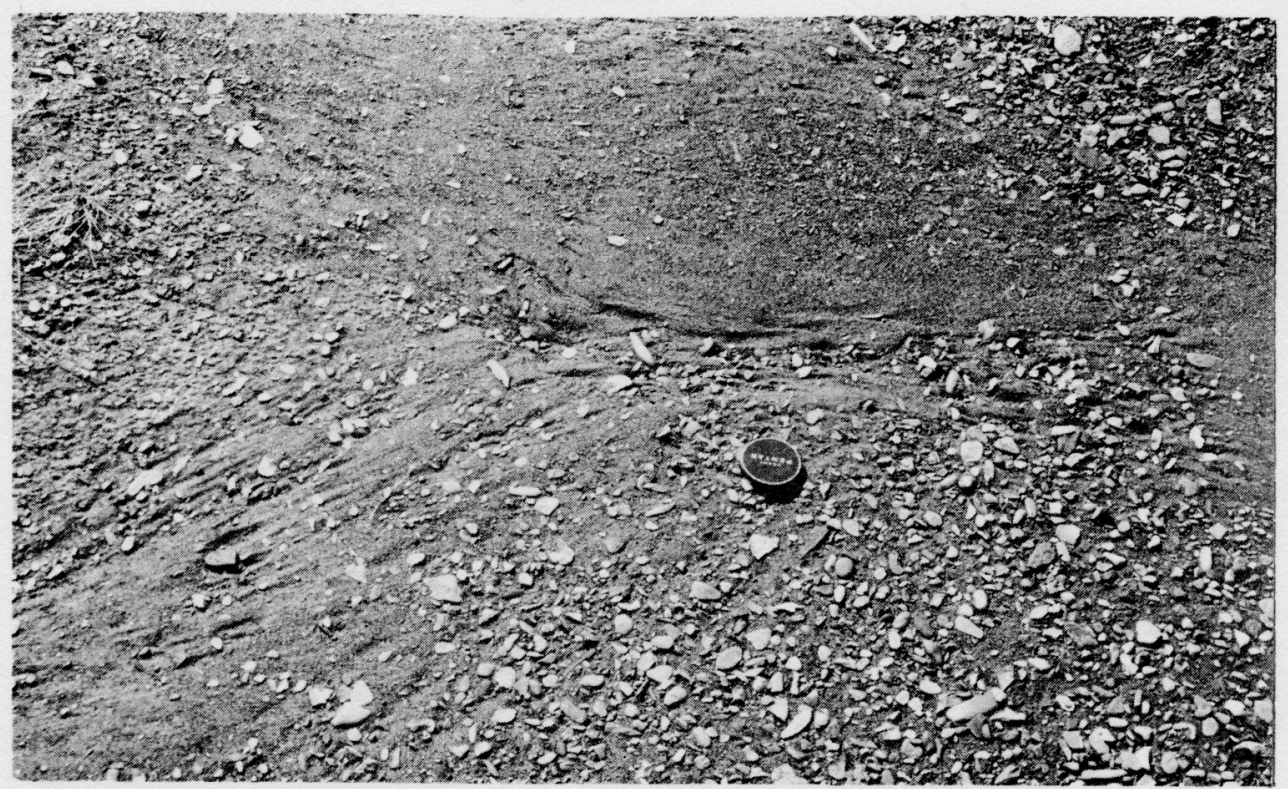

Figure 4 - Sand and silt trapped in a bar depression.

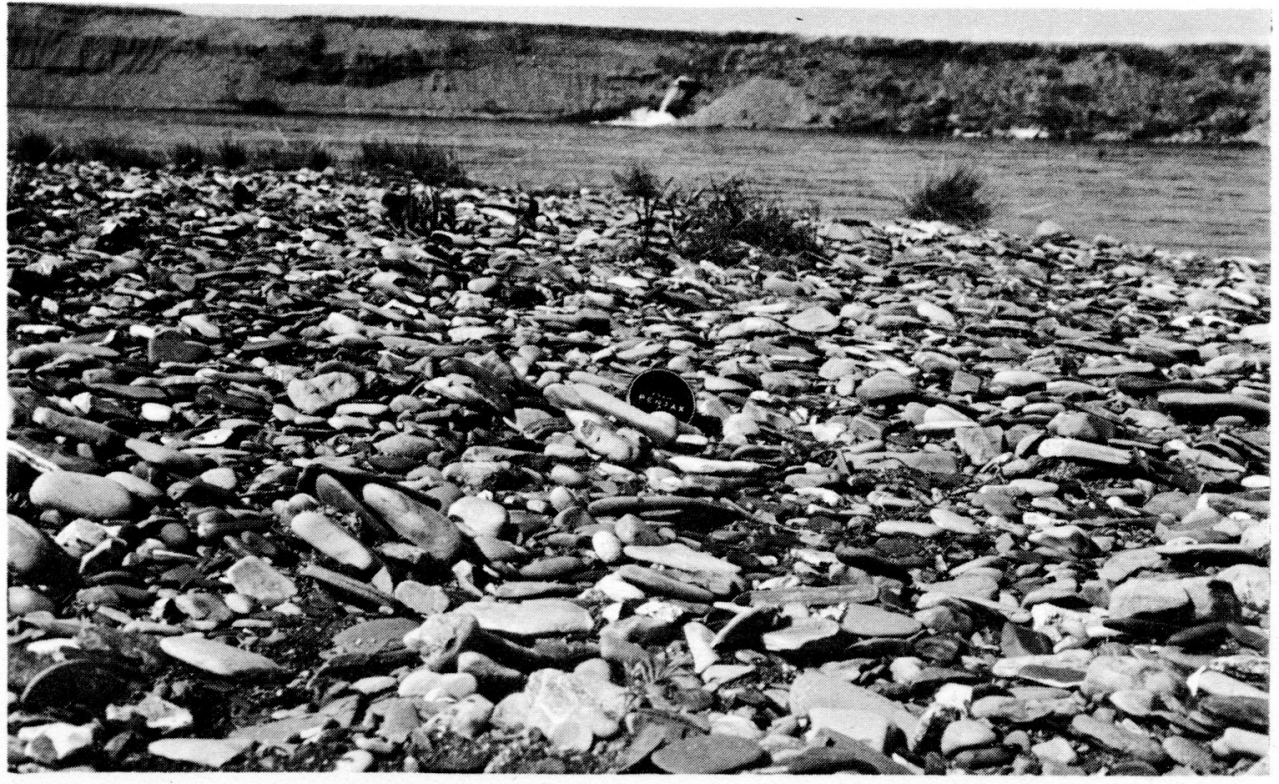

Figure 5 - Imbricated cobbles on a dry bar. The direction of flow across the bar is from right to left. 


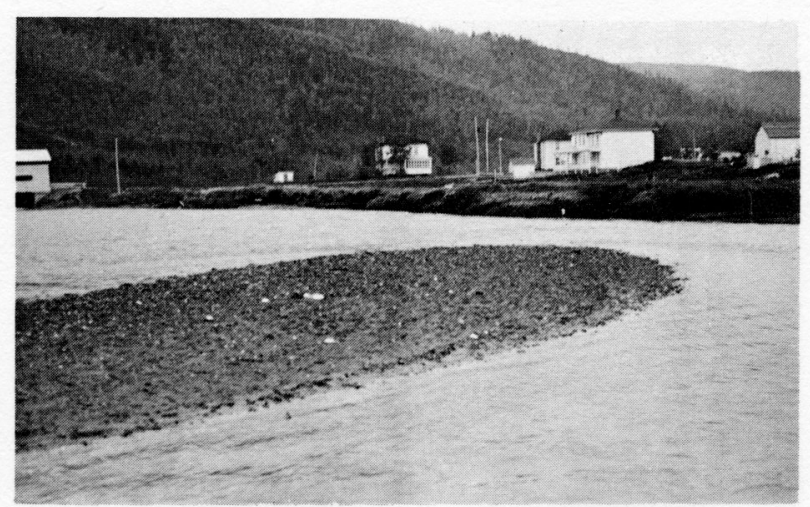

Figure 6 - Planed-off tidal bar emerging at low tide. Silts and sand are swept to the downstream end of the bar nearest the observer.

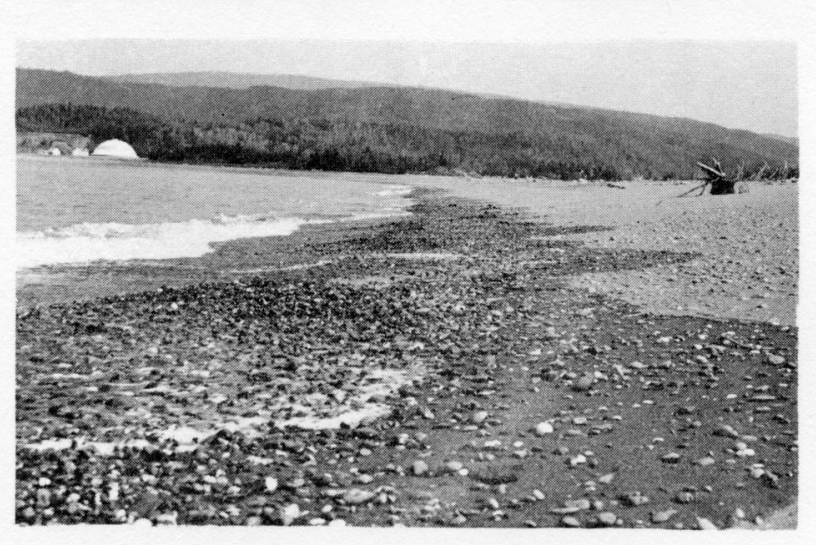

Figure 7 - Long, sandy gravel spit at Riviere Madeleine.

The sweeping of the sediment from the bar surface leaves the tidal bars with a flat, planedoff surface (Fig. 6). During the falling tide, the sides of the newly exposed bar are trimmed and terraced. Sands that are swept from the bar surface and deposited in the deeper pools before the less face of the bar are eroded once more. Small streams draining the bar surfaces during the falling tide erode pebbles and coarse sand and cut small gullies into the bar surface. These depressions are refilled, and the surface of the bar is left planar with the next tidal rise.

The tidal bars are located in wider reaches of the lower river, where the local flow velocity is decreased. The tidal bars appear to have a lower rate of migration than the midchannel bars of the upper river reaches. This observation is in keeping with the periodic waning strength of the flow in the lower, tide-affected reaches of the rivers.

The tidal bars are deposited up to the vicinity of the beach. From here the gravels spread out as sheets or cones from the mouths of the rivers. As happens at Riviere Madeleine, the gravels can be incorporated into spits which build across the river mouths and force a change in the direction of flow of the river itself (Fig. 7).

\section{Conclusions}

The tidal gravel bars are a sediment-storage phenomenon. All grades of sediment are transported and deposited here. Sediments of different sizes are then preferentially removed to the intertidal area by the varying seasonal runoff. Being the coarsest sediment present, and therefore the most difficult to transport, the gravels form most of the tidal bars and remain there until the river flow has the competency to transport them to the beach and beyond.

\section{References cited}

ENOS, P., 1969, Cloridorme Formation, Middle Ordovician flysch, northern Gaspé Peninsula, Quebec, Geol. Soc. Amer. Spec. Paper 117.

HJULSTROM, F., 1935, Studies of the morphological activity of rivers as illustrated by the River Fyris, Univ. Upsala Geol. Inst. Bul1. 25, p. 221-527.

LEOPOLD, L.B. and WOLMAN, M. G., 1957, River channel patterns-- braided, meandering, straight,U.S. Geol. Surv. Prof. Paper 282B. 